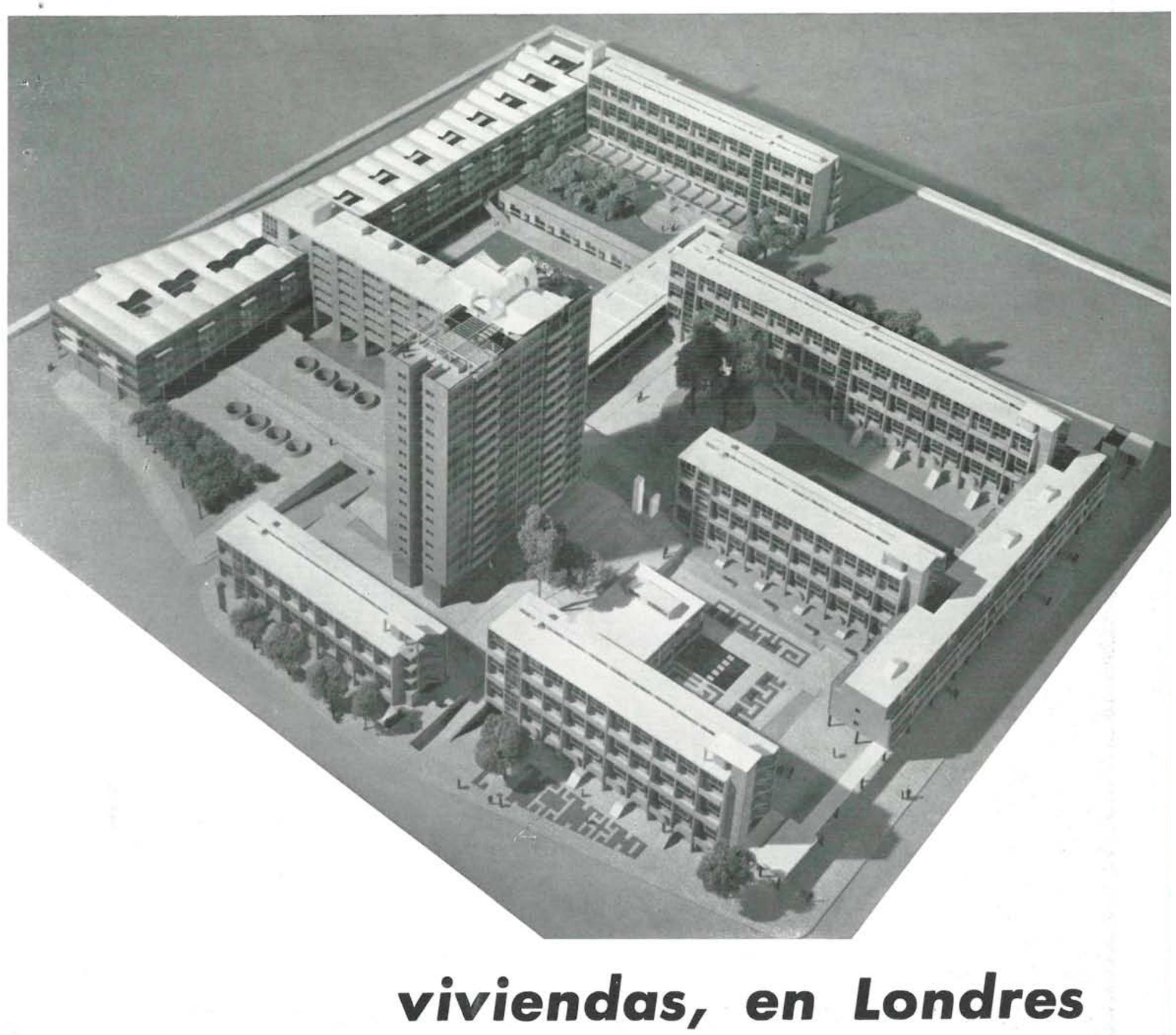

Este conjunto residencial, previsto para albergar un total de 1.400 personas en 559 viviendas, se levanta sobre un solar de unas $3 \mathrm{Ha}$, barrido por los bombardeos de la pasada guerra y sin características especiales. Está proyectado para una densidad de población de 500 personas por hectárea.

Las viviendas son de programa muy variado, desde 1 hasta 4 habitaciones, distribuyéndose en cuatro bloques de pisos en un solo nivel, con 371 viviendas, y cinco bloques de viviendas en "dúplex", con 188 unidades. Completan el grupo, un centro comercial, otro recreativo y deportivo, solar destinado a escuelas primarias, sistema de calefacción y agua caliente centralizados y, finalmente, multitud de patios 


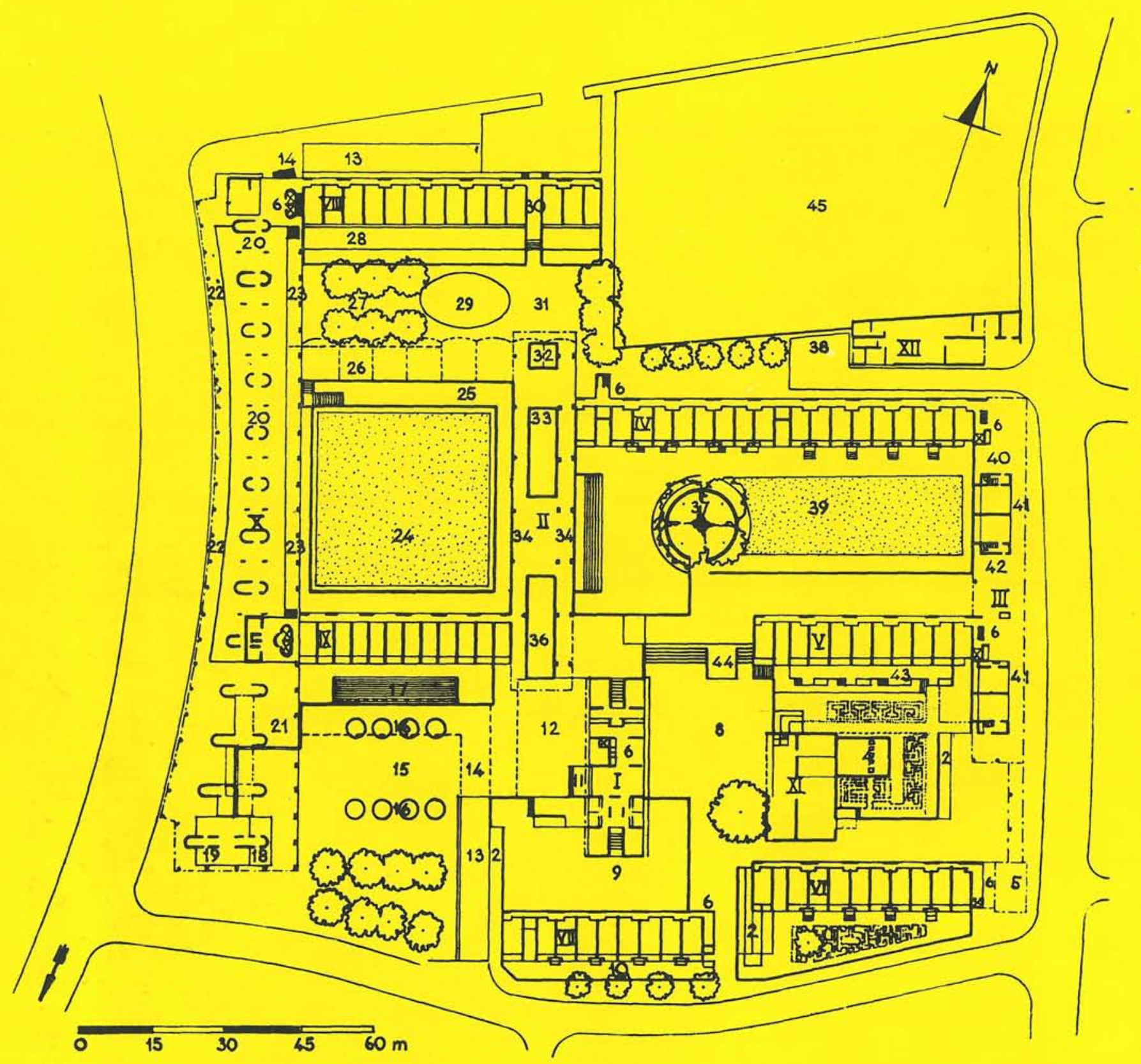

\section{Emplazamiento general}

I. Gran Casa Arthur: 16 pisos, 120 viviendas de 2 habitaciones, en 15 plantas. Oficina general de administración, lavaderos, etc., en la I. Gran Casa Arthur: 16 pisos, 120 viviendas de 2 habitaciones, en 15 plantas. planta baja, cuartos auxiliares en el sotano.- - II. Centro Casa Basterfield: 6 pisos; 54 apartamentos de 3 y 4 habitaciones. $-\mathrm{V}$. Casa Bayer hen: 4 pisos, 32 vimentos de 3 y 4 habitaciones.-VI. Casa Bowater: 6 pisos, 30 apartamentos de 3 y 4 habitaciones.-VII. Casa Cuthbert 6 prrowing 4 pisos, 18 apartamentos de 3 y 4 habitaciones,-vir. Bloque en la calle Baltic (proyectada): 6 pisos, 42 apartamentos de 3 y 4 habitaciones con planta adicional de 14 viviendas de 1 habitacion. $-1 X$. Bloque Bowling Green (proyectado): 6 pisos, 72 viviendas de 1 habitación. $X$. Bloque en la calle Goswell (proyectado): 4 pisos, 147 viviendas, la mayoria de 2 y algunas de 3 habitaciones, con de 1 habitacion. - h. Bésped en 3 plantas sobre almacenes. - XI. Edificio común: hall al nivel bajo, en el sótano salas de club. - XII. Talle común: sirve todos los bloques.

1. Acceso cubierto para peatones.-2. Rampa para peatones hacia el patio y los almacenes en el sótano.-3. Patio de bajo nivel y jardín cuidado.-4. Estanque.-5. Paso cubierto.-6. Entrada para los bloques de viviendas. - 7. Patio de bajo nivel con hierba y pavimento. 8. Plaza principal. -9 . Patio pavimentado de nivel bajo al sur de la nave de calderas. 10 . Patio de divel ba Harrowing. - 11. Paso abierto bajo el edificio Arthur.-12. Nave de calderas debajo del nivel bajo. subterranea de servicio,-14. Carretera subterranea de servicio. - 15. Patio de peajo del bloue IX - 18. Restaurante-19. Edificio público. ( 20. Tiendas. - 21. Paso ablerto por debajo de bloqu 25. Terraza del club.-26. Club de los residentes, al nive baso - por debajo del bloque VIII. - 31 . las viviendas de Plaza de Juego para ninos perio paso por debajo del Espacio abierto debajo del edificio Stanley Cohen. vicio para los talleres. - 39. Patio a sur del dificio Bayer -44. Plinto para escultura, -45 , Solar para la escuela primaria futura de L. C. C. 


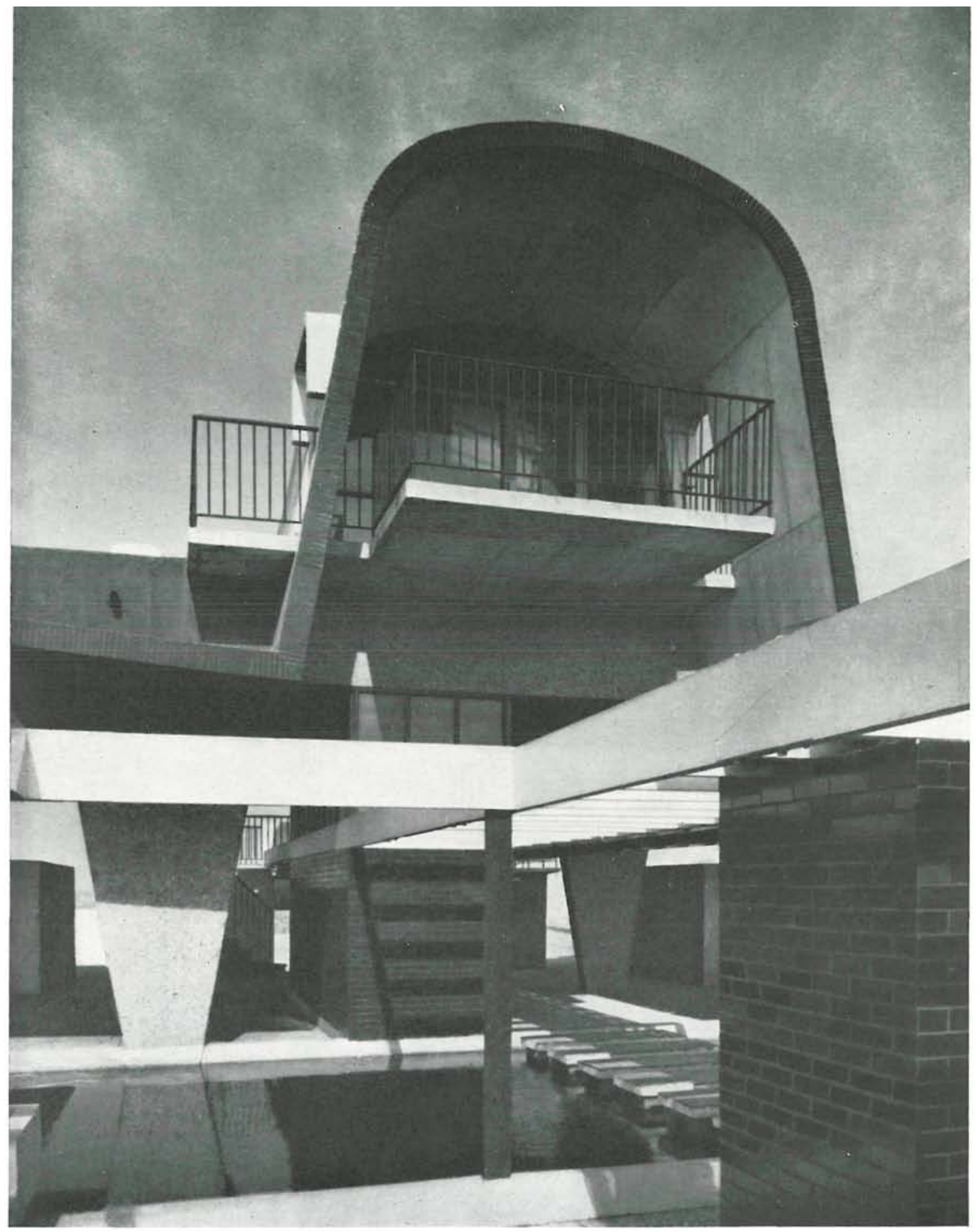

y jardines a distintos niveles y con diferentes usos y decoración, destinados a proporcionar ambientes gratos y zonas de juego para los niños, retiradas del tráfico rodado, el cual se lleva a cabo por las vías públicas perimetrales o por otra subterránea que atraviesa el solar de norte a sur. Con este objeto, se han dispuesto los ascensores, escaleras, vertederos de basuras, etc., lo más próximos posible a esas calles que limitan el solar o al paso inferior.

Todas las viviendas son así exteriores, satisfaciendo esa necesidad primordial de luz, ventilación y vistas a amplios y variados patios o a las propias calles. 

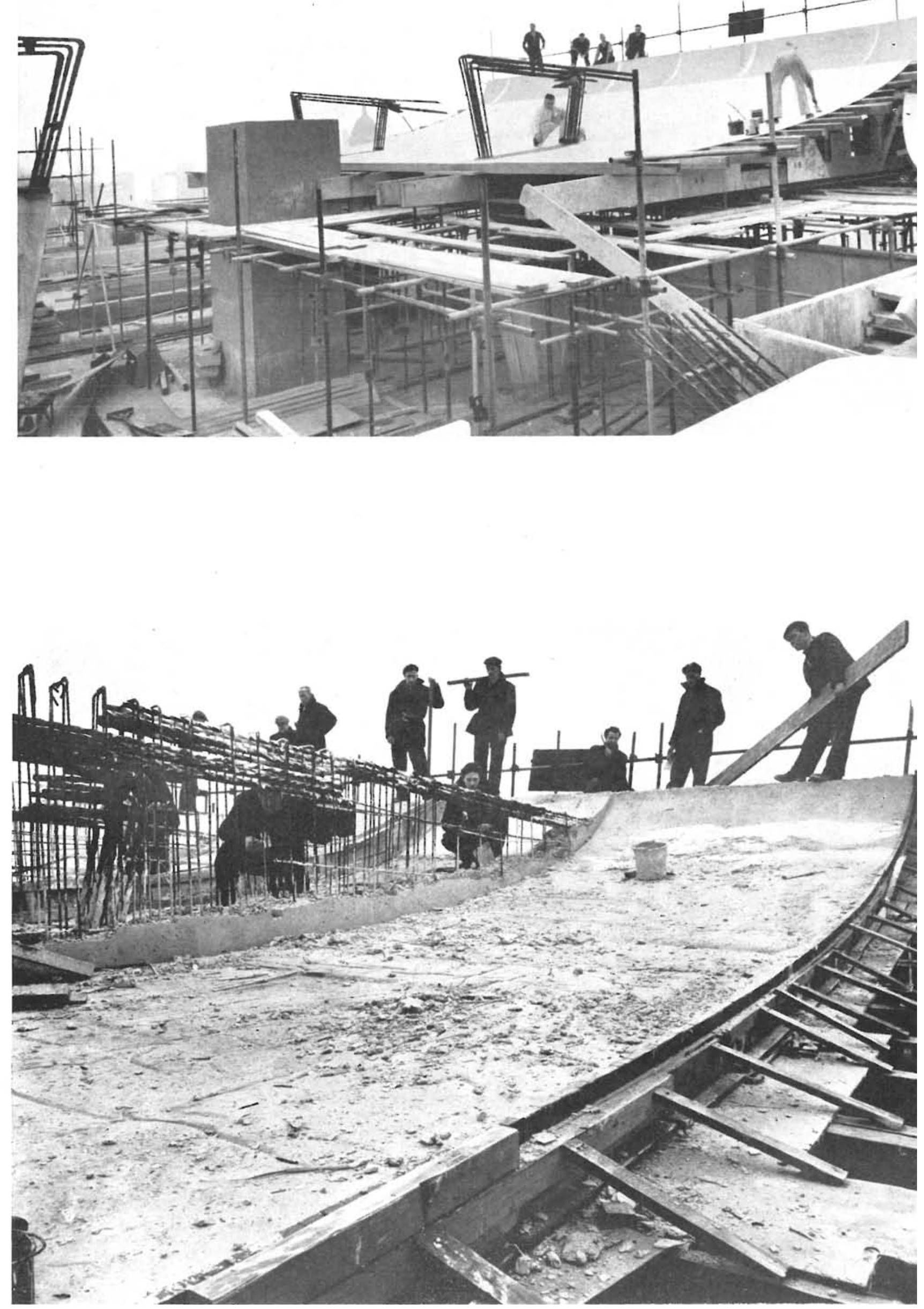
PLANTA de Calderas y Sotanos de almacenes

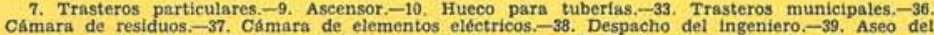

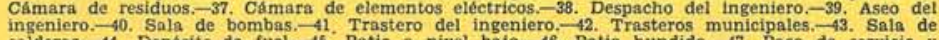
calderas.-44. Deposito de fuel.-45. Patio a nivel bajo. 46. Patio hundido.-47. Paso de servicio y rampa de subida al nivel de ta calle.
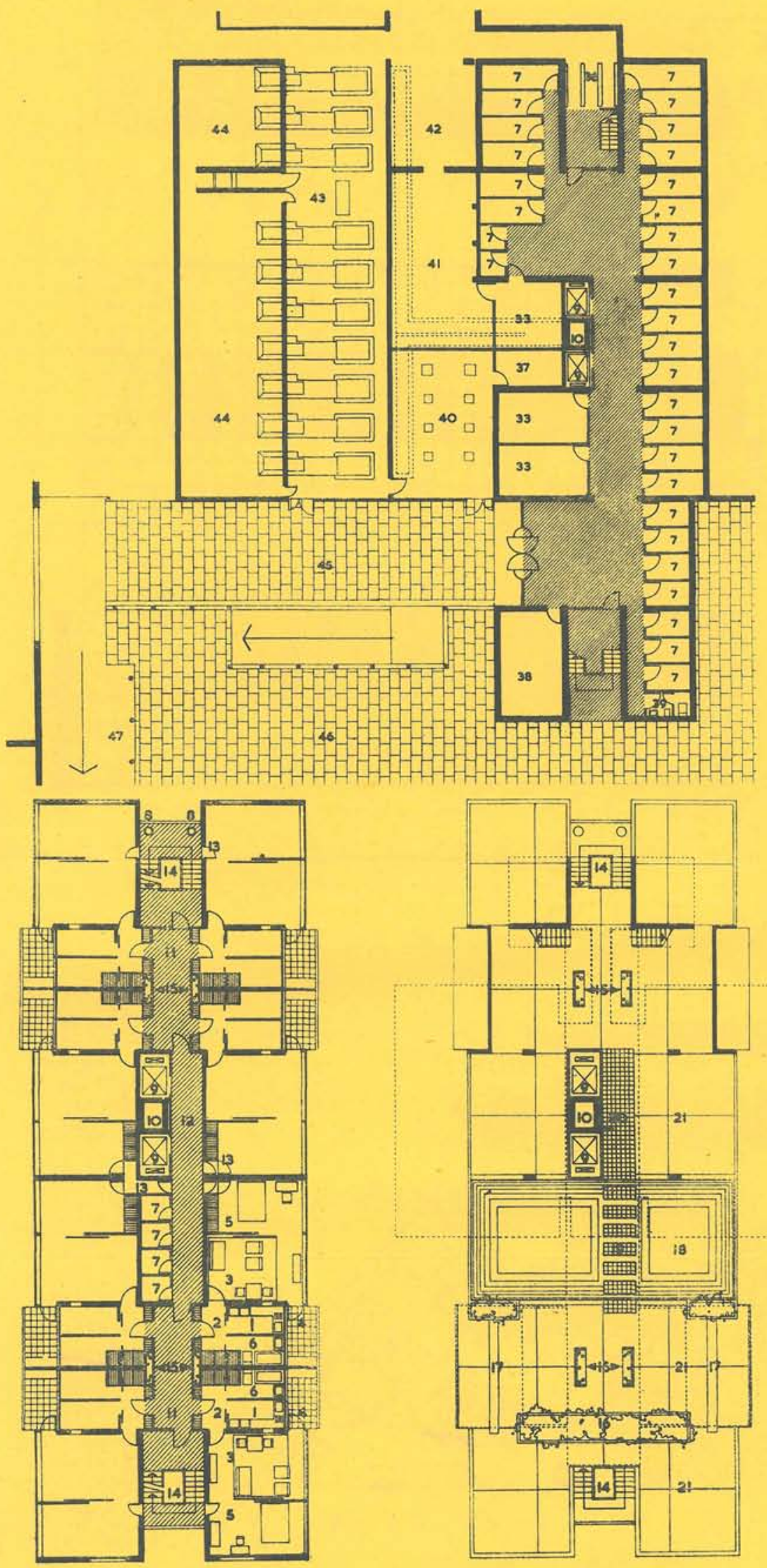

PLANTA TIPO

1. Cocina -2 . Vestibulo -3 . Estar. $\rightarrow$, Terraticular. - 3. Vertedero basuras. -9 . Ascensor-

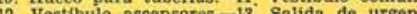
cia.-14. Escaleras públicas. -15 . Hueco de con-

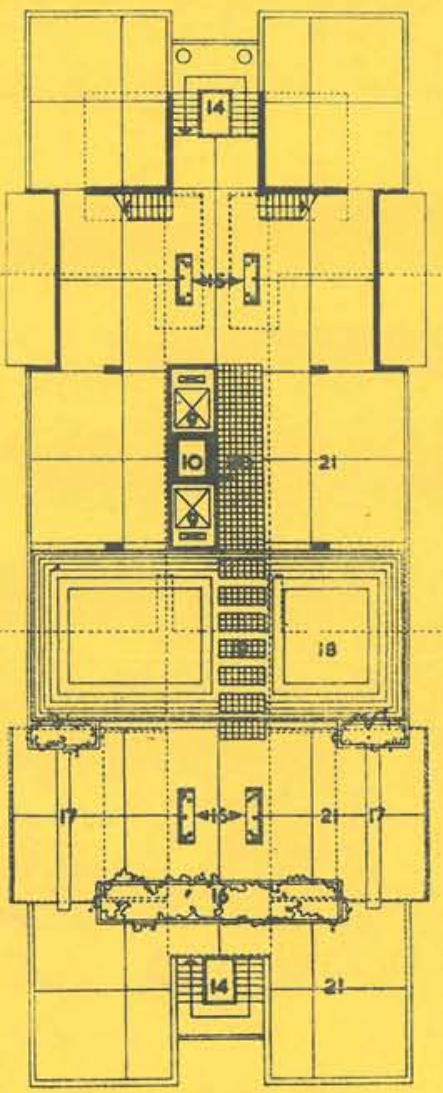

PLANTA dE TERRAZAS

9. Ascensor, - 10. Hueco para tuberias. -14 . Es. caleras púbicas. -15 . Hueco de conductos. -16 . Plataforma pavimentada, -21 . Pavimento de
ENTRADA A LA PLANTA BAJA 9. Ascensor, -10 . Hueco para tuberlas, - 14. Escaleras publicas.-
15. Hueco de conductos. - 28. Oficinas, -29 . Oficinas municipales.33. Trastero municipat-34. Sala de lavado y secado -35 . Habita ción thobbyn.
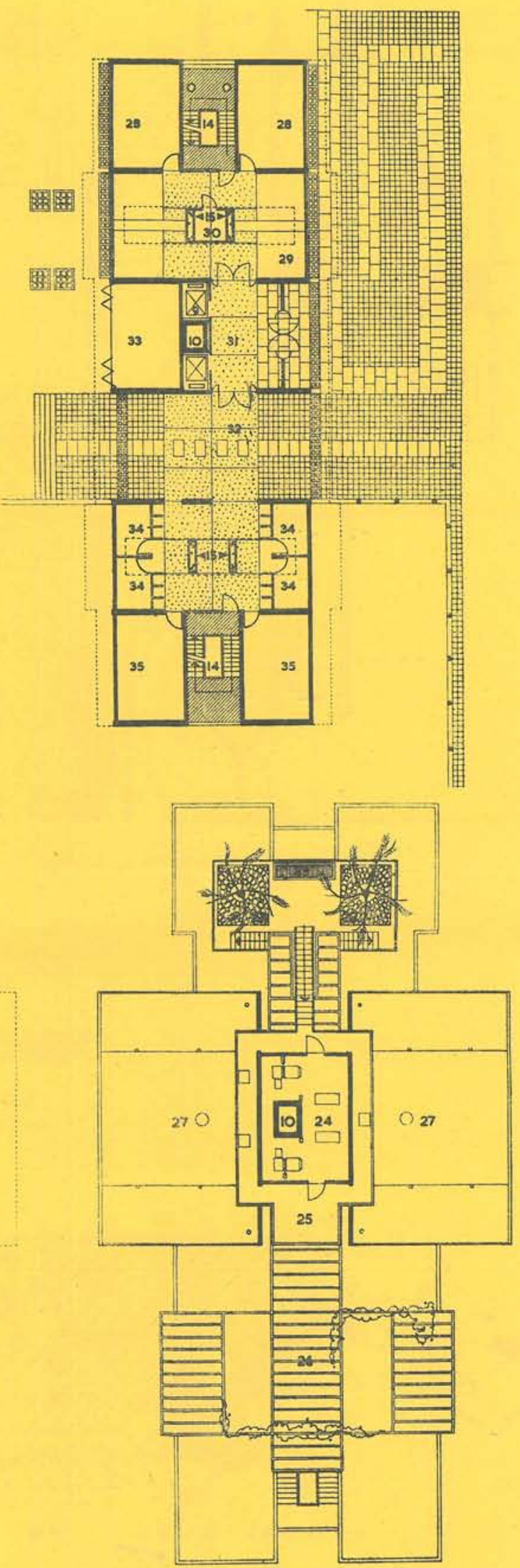

SALA DE MAQUiNAS dE ASCENSORES

22. Empedrado alrededor de los árboles. -23 . Rejilla sobre el hueco de escalera. -24 . Salin de
ascensores. -25 . Mirador. -26. Pérgola. - 27. De- 

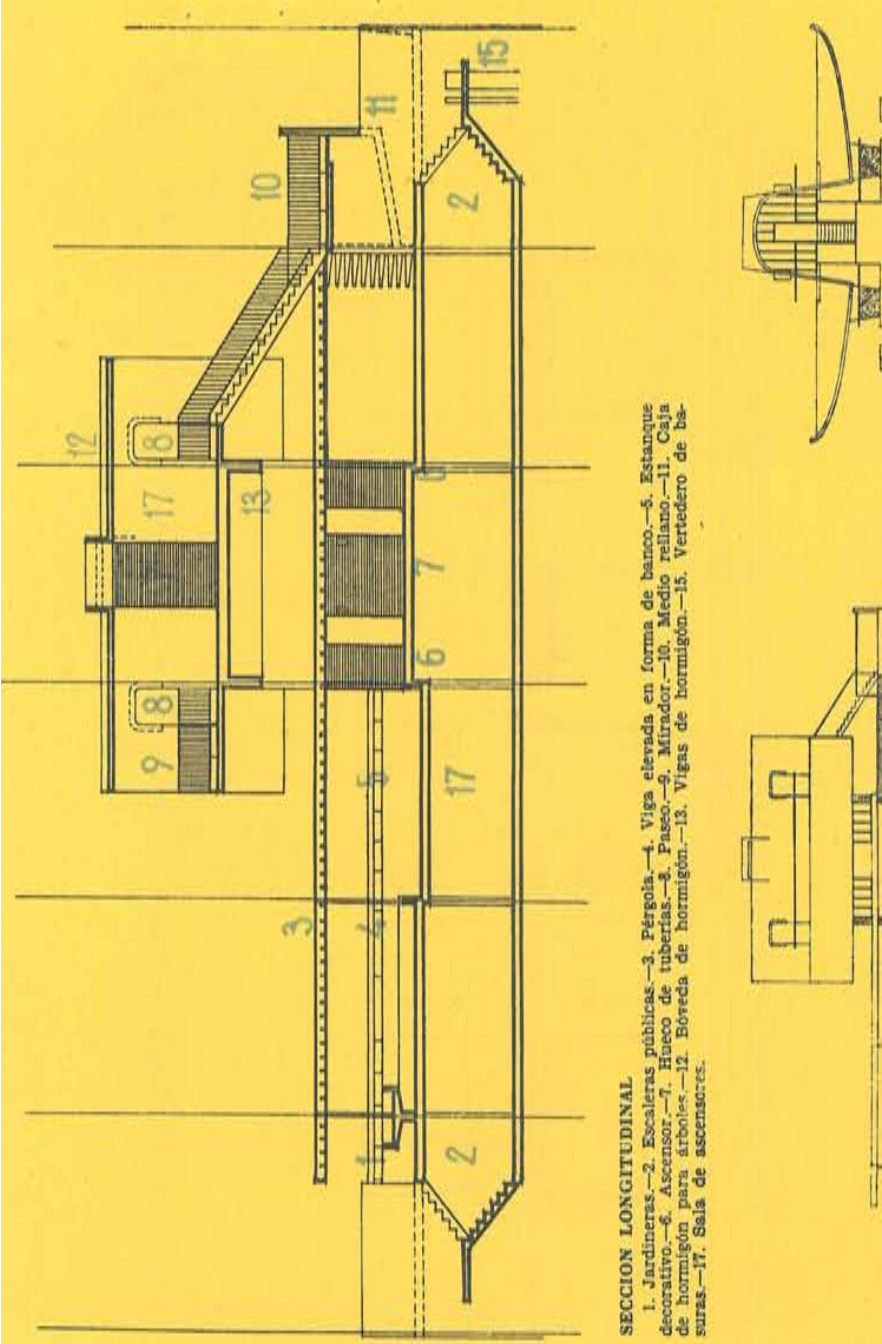

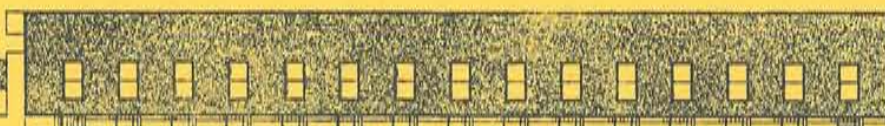

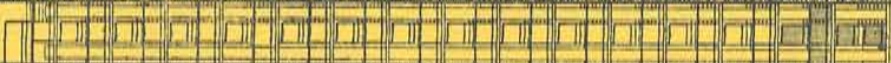

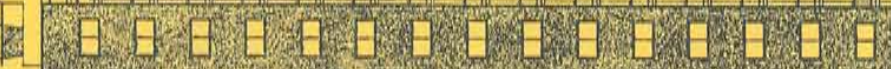
\begin{tabular}{|c|c|c|c|c|}
\hline & 0 & \\
\hline
\end{tabular}

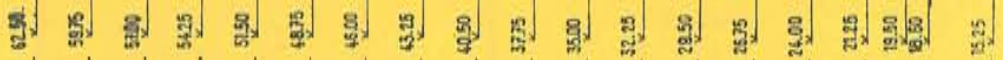
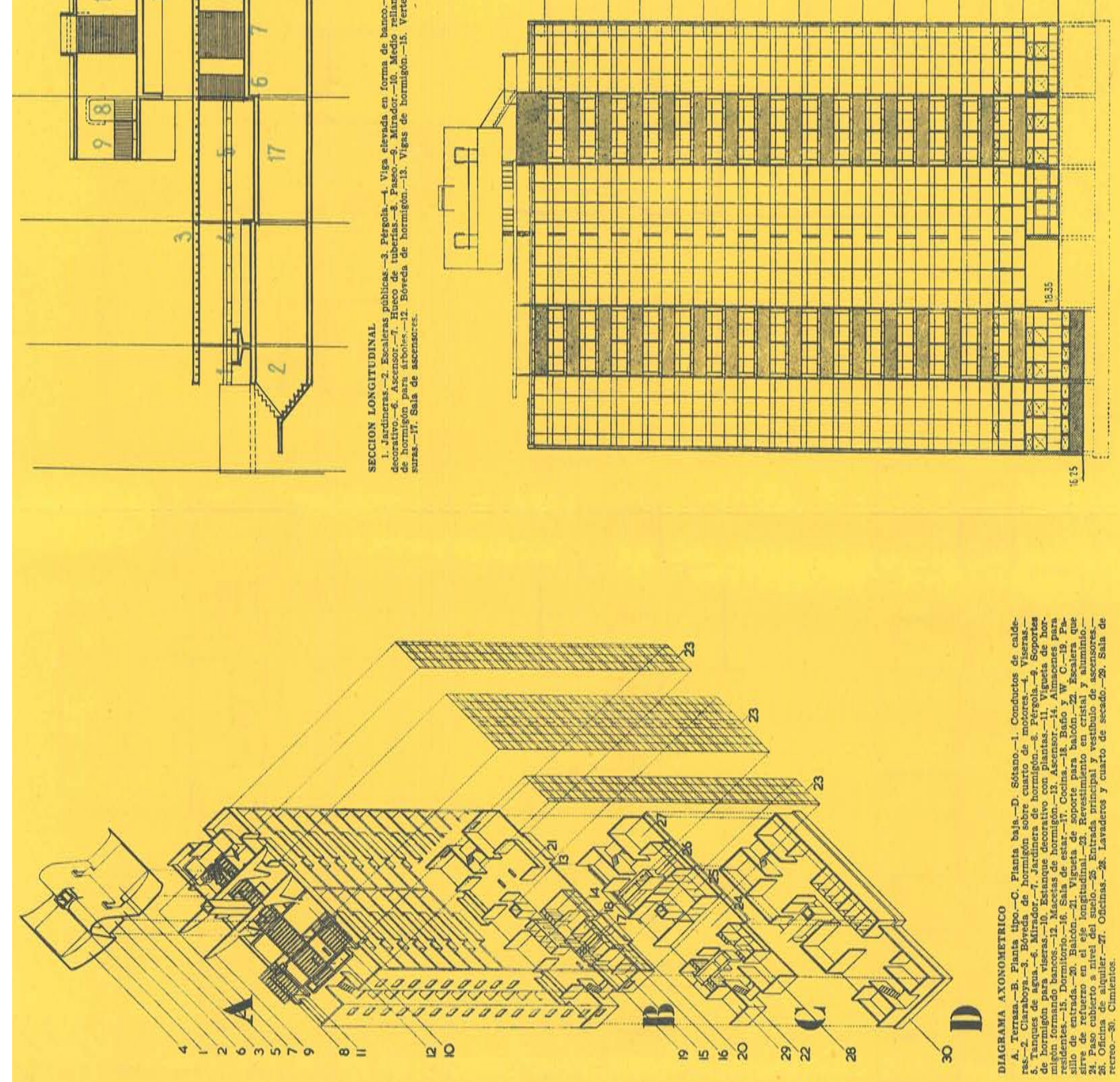


\section{escalera lateral alzado a patios particulares}

Todos los bloques están compuestos en cuatro y seis alturas, salvo las zonas comerciales y de recreo y la torre central de quince plantas, que subraya un elemento de verticalidad acusada, como nota de contraste y composición de forma, a la vez que se ha estudiado cuidadosamente el conjunto de sombras arrojadas, de modo que el sol pueda dominar siempre y llevar a todos los hogares su mensaje luminoso de salud y alegría.

El bloque alto comprende 120 viviendas de dos habitaciones, con ocho viviendas por planta, un pasillo central de comunicación, dos ascensores, cuatro trasteros y dos escaleras de emergencia en los extremos norte y sur de la planta. La plan-

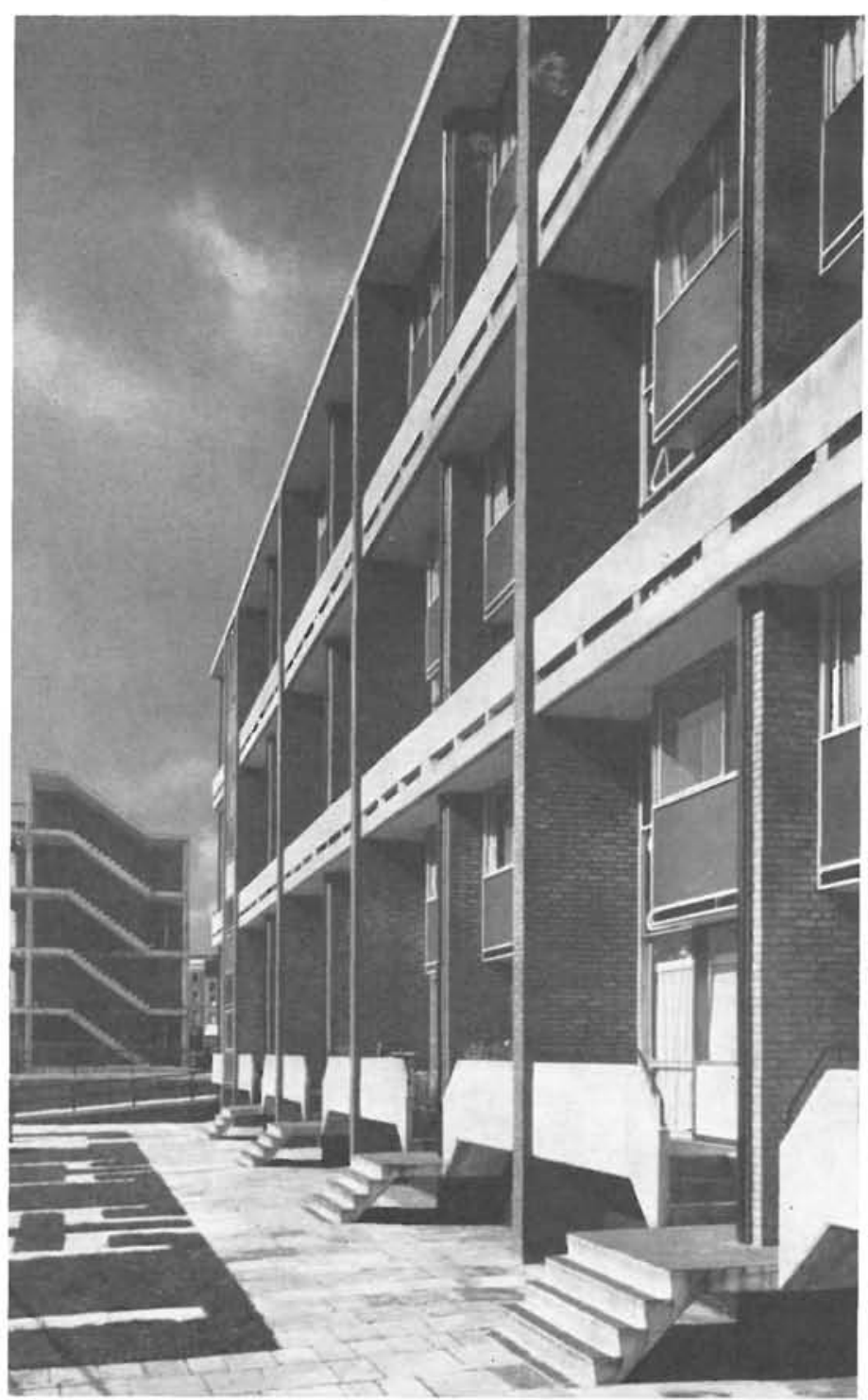

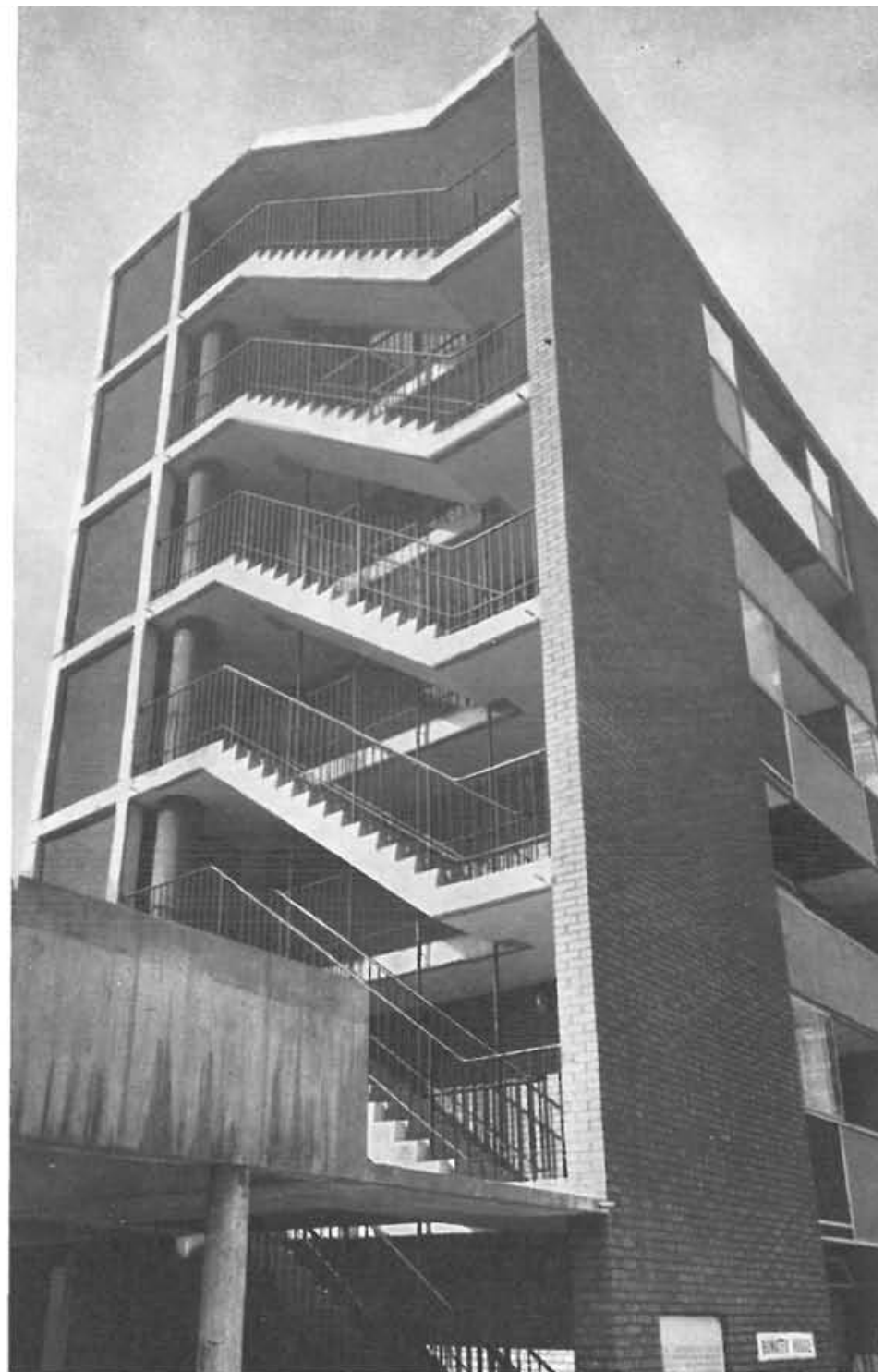

ta baja está destinada a oficinas y lavaderos. Cada piso consta de: vestíbulo, aseo, cocina, dormitorio, estar-comedor y armarios empotrados. La cubierta-terraza está decorada como jardín, con láminas de agua, al objeto de servir de expansión a las plantas altas del edificio que se hallan muy separadas del suelo. Destacan, sobre la cubierta, dos viseras simétricas de atrevido diseño, las cuales soportan sendos depósitos de agua y sirven, también, para dar variedad de línea al bloque prismático, uniéndose a esta labor con las hendiduras de las escaleras laterales y las fachadas principales compuestas a base de cristal y elementos esmaltados. 

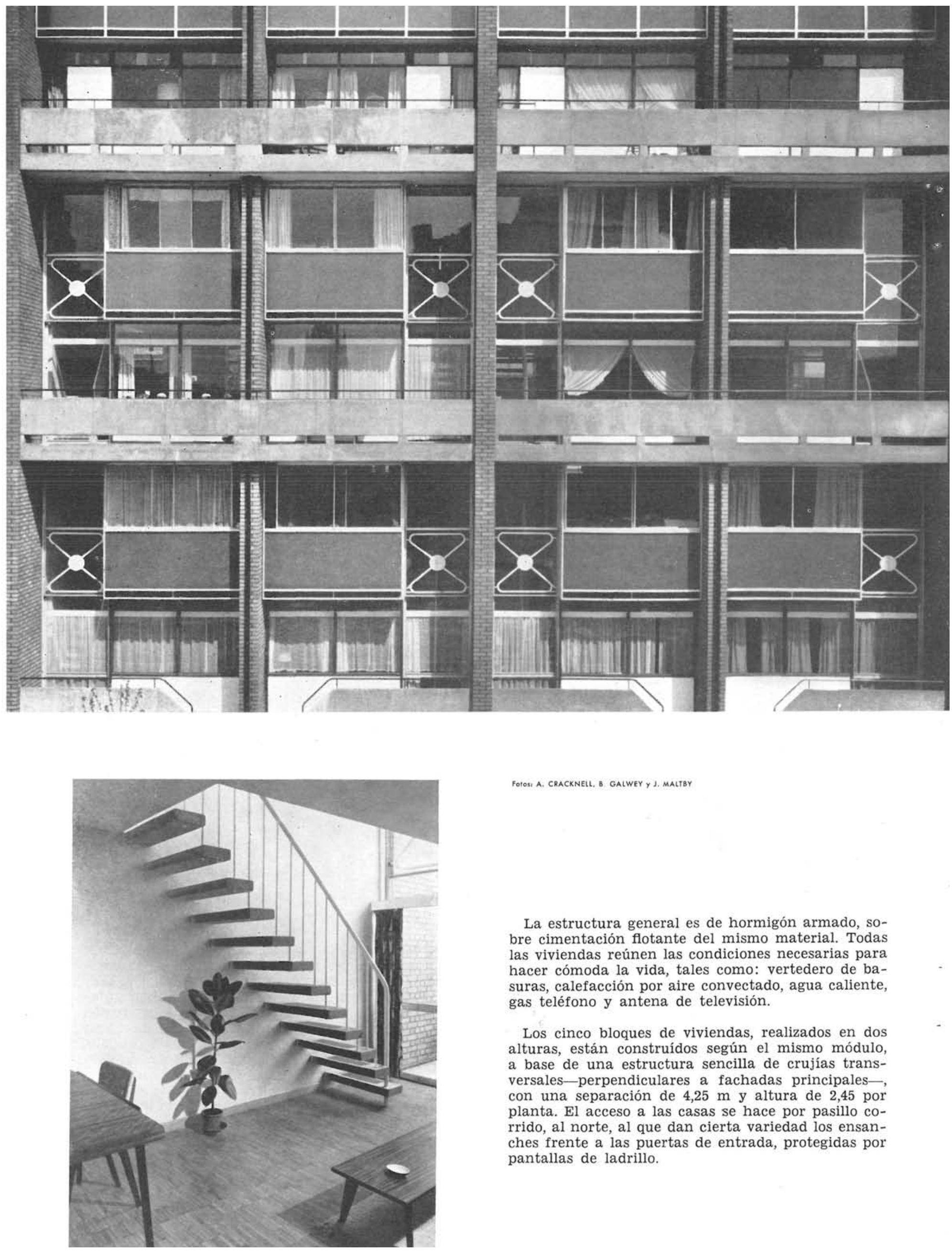

Fotos: A. CRACKNEIL, B. GALWEY Y J, MALTBY

La estructura general es de hormigón armado, sobre cimentación flotante del mismo material. Todas las viviendas reúnen las condiciones necesarias para hacer cómoda la vida, tales como: vertedero de basuras, calefacción por aire convectado, agua caliente, gas teléfono y antena de televisión.

Los cinco bloques de viviendas, realizados en dos alturas, están construídos según el mismo módulo, a base de una estructura sencilla de crujías transversales-perpendiculares a fachadas principales-, con una separación de $4,25 \mathrm{~m}$ y altura de 2,45 por planta. El acceso a las casas se hace por pasillo corrido, al norte, al que dan cierta variedad los ensanches frente a las puertas de entrada, protegidas por pantallas de ladrillo. 


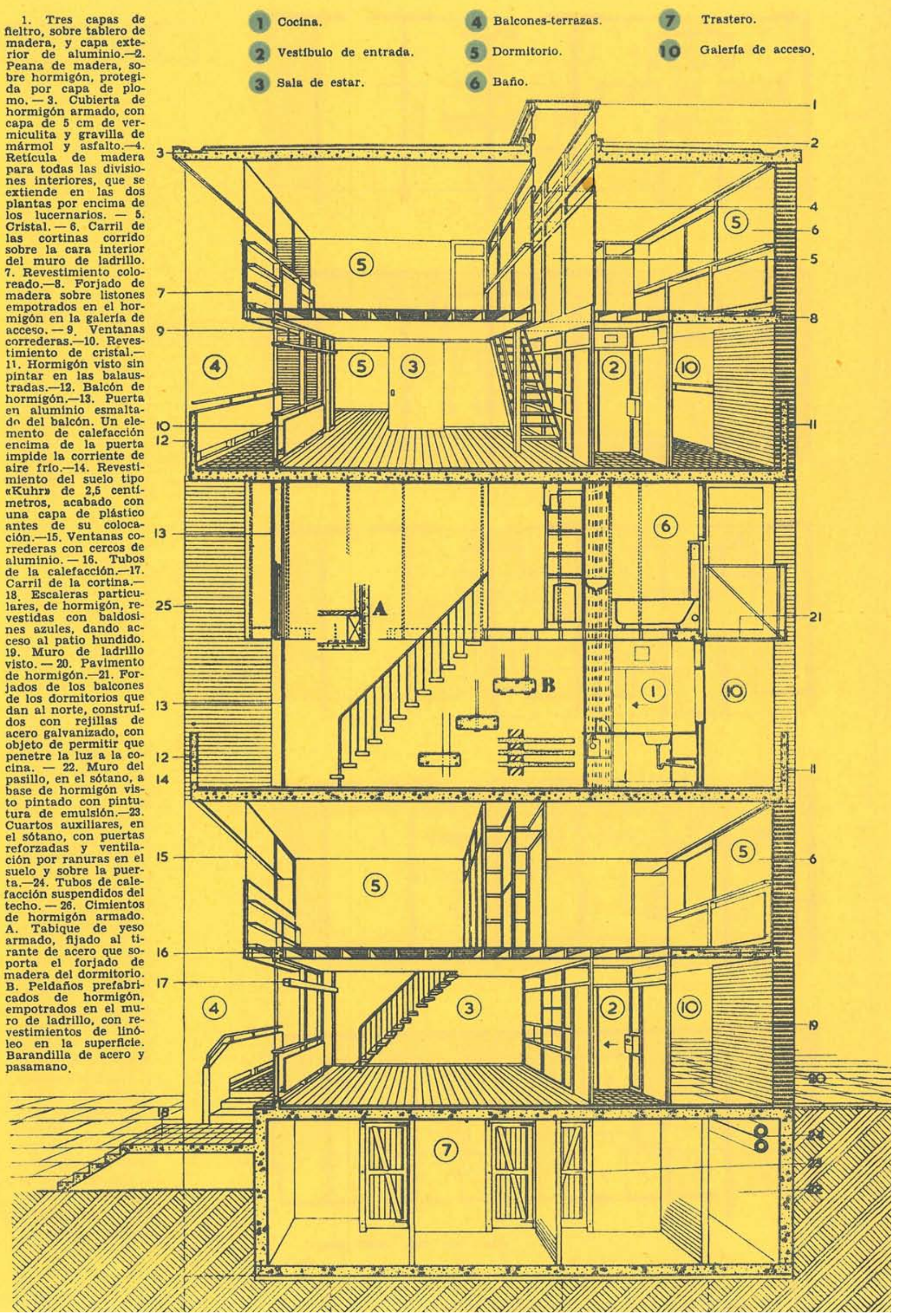



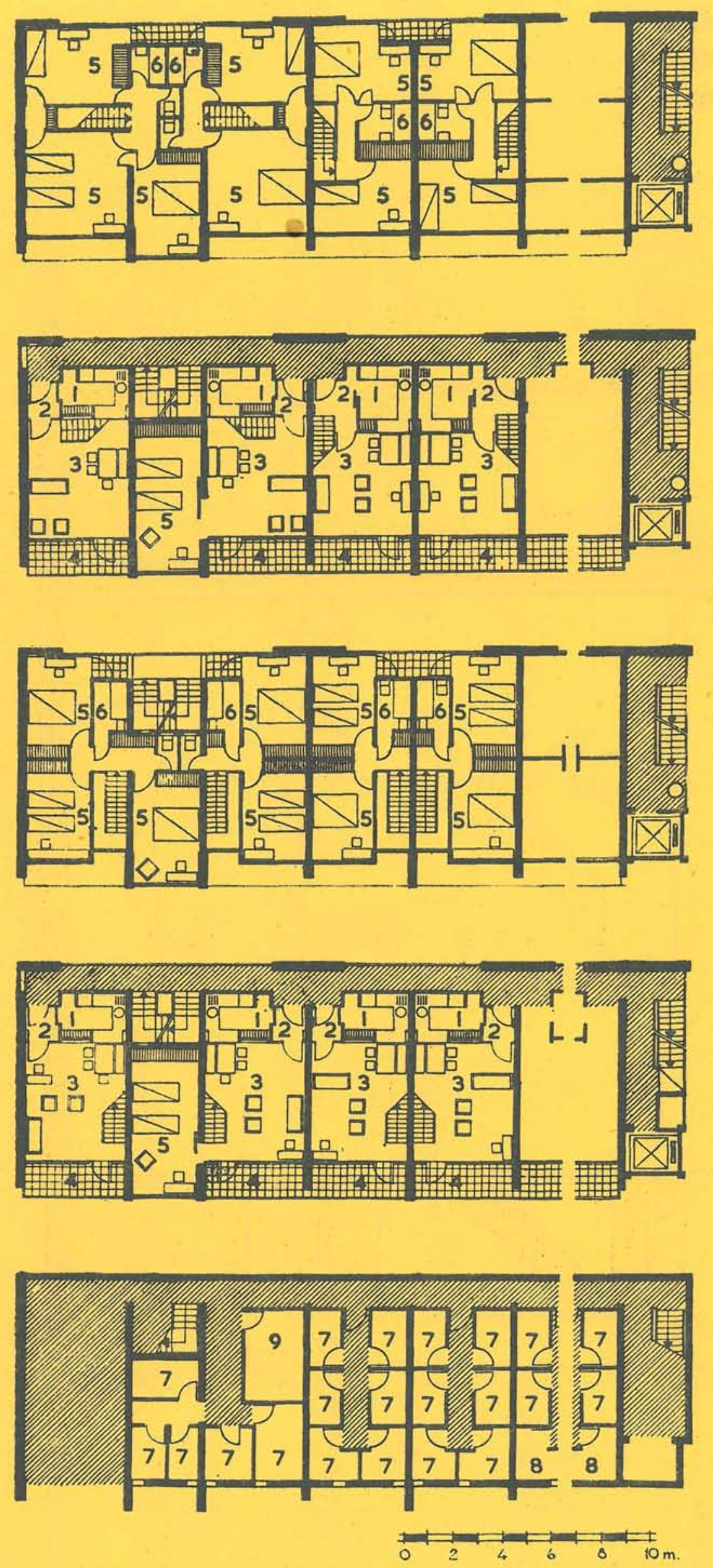

1. Cocina.-2. Vestíbulo de entrada.3. Sala de estar. -4 . Balcones-terrazas. 8. Lavaderos, -9 . Control de calefacción.
Hay dos tipos de pisos: con tres dormitorios y con dos; el resto de las estancias es idéntico: estar - comedor, vestíbulo, cocina, baño y terraza. La estructuración fundamental se acusa con sinceridad en las fachadas. En la fachada principal aparece la retícula que deflne abiertamente el sistema ordenador $y$ el número de viviendas, buscando el retranqueo en terrazas con fondo de cristal y material esmaltado, lo cual presta ligereza, variedad, color y fuertes sombras contrastantes al conjunto. Las propias escaleras, vistas y descubiertas, marcan un ritmo diagonal, ciertamente convincente, que tiende a distraer el juego dominante $y$ perpendicular de los alzados. 